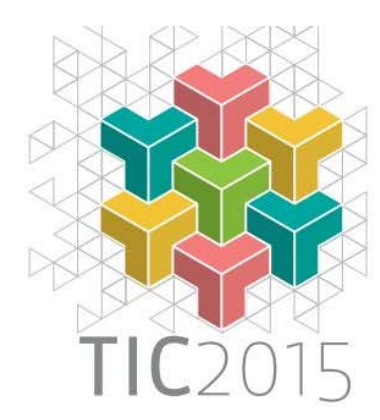

\title{
A INTRODUÇÃO DO BIM EM CURSOS DE ARQUITETURA E URBANISMO: RELATO COMPARATIVO DE DUAS EXPERIÊNCIAS ${ }^{1}$
}

\author{
INTRODUCTION TO BIM IN ARCHITECTURE AND URBANISM \\ EDUCATION: COMPARATIVE REPORT OF TWO SCENARIOS
}

\author{
Neliza Maria e Silva Romcy \\ Universidade Federal do Rio Grande do Norte (UFRN) \\ neliza.romcy@gmail.com \\ Marcelo Bezerra de Melo Tinoco \\ Universidade Federal do Rio Grande do Norte (UFRN) \\ mmarcelotinoco@gmail.com \\ Daniel Ribeiro Cardoso \\ Universidade Federal do Ceará (UFC) \\ danielcardoso@ufc.br
}

\begin{abstract}
Resumo
No Brasil, relatos de experiências mostram uma evolução nas discussões sobre o Building Information Modeling (BIM), mas a adoção do tema nos cursos de graduação ainda é introdutória e vem acontecendo de forma pontual em disciplinas. O BIM pode ser definido como a criação e uso de informação computacional coordenada e consistente sobre o projeto de uma edificação. Nesse contexto, o presente artigo tem como objetivo apresentar a experiência de introdução do BIM no curso de Arquitetura e Urbanismo de duas universidades federais, assim como sua repercussão e apropriação por parte dos alunos. O método utilizado incluiu: 1) etapa de caráter descritivo, onde foi levantado o histórico de implementação do BIM para cada universidade, considerando estrutura curricular e disciplinas; 2) etapa de caráter exploratório, onde foi realizada a aplicação de questionário junto a estudantes de disciplinas de projeto. Relacionando os resultados dos questionários com os históricos de implementação previamente descritos, foi possível estabelecer comparativos entre as experiências, refletir sobre possíveis estratégias e trazer desafios a serem ainda superados. Assim, o trabalho pretende contribuir para o estado da arte e trazer reflexões a partir dos resultados levantados junto aos estudantes que passaram por essas mudanças iniciais.
\end{abstract}

Palavras-chave: Building Information Modeling. Ensino. Projeto Arquitetônico.

\begin{abstract}
Experiences reports in Brazil show an evolution concerning to discussions about Building Information Modeling (BIM), but its adoption in undergraduate education is still introductory and applied on sporadic courses. BIM refers to the creation and use of coordinated, consistent, computable information about a building project in design. In this context, the paper aims to present the introduction of BIM in Architecture and Urbanism undergraduate courses of two federal universities, as well as its impact and adoption by the students. The methodology includes: 1) a descriptive stage, in order to describe the context for each university, considering curriculum and courses; 2) a exploratory stage, in order to present the application of a questionnaire to the students. Relating the questionnaires results to the context previously described allows comparisons between the scenarios and reflections on possible strategies and challenges yet to overcome. Thus, the work aims to contribute to the
\end{abstract}

\footnotetext{
${ }^{1}$ ROMCY, N. M. S.; TINOCO, M. B. M.; CARDOSO, D. R. A introdução do BIM em cursos de arquitetura e urbanismo: relato comparativo de duas experiências. In: ENCONTRO BRASILEIRO DE TECNOLOGIA DE INFORMAÇÃO E COMUNICAÇÃO NA CONSTRUÇÃO, 7., 2015, Recife. Anais... Porto Alegre: ANTAC, 2015.
} 
discussion on the subject and think over the results collected from students who went through those initial changes.

Keywords: Building Information Modeling. Teaching. Architecture Design.

\section{INTRODUÇÃO}

O Building Information Modeling (BIM) pode ser definido como a criação e uso de informação computacional coordenada e consistente sobre o projeto de uma edificação informação paramétrica usada para tomada de decisões em projeto, produção de documentação com qualidade, previsão do desempenho da edificação, estimativa de custo e planejamento de obra (KRYGIEL; NIES, 2008). Assim, consiste em uma metodologia para gerenciar os projetos e seus principais dados, em formato digital, ao longo do ciclo de vida de uma construção (PENTTILÄ, 2006 apud SUCCAR, 2009).

$A$ adoção do BIM no ensino varia de universidade para universidade, tanto no Brasil como no exterior, não existindo ainda um consenso sobre como pode ser feito ou qual o melhor momento na formação do estudante para se trabalhar com o tema. No cenário nacional, relatos de experiência mostram que houve evolução nas discussões sobre o tema nas universidades, mas a adoção do BIM nos cursos de graduação ainda é introdutória e vem acontecendo de forma pontual em algumas disciplinas dos cursos (CHECCUCCI, 2014).

Segundo Ruschel (2014), a transição do processo de projeto analógico para o processo de projeto auxiliado por computador foi menos traumática no passado e obteve maior aceitação primeiramente na academia e depois na prática - o inverso do cenário atual. Apesar do benefício econômico para construtores estar sendo perseguido pela construção brasileira, a motivação ainda não parece suficientemente forte para a academia na área de Arquitetura e Urbanismo.

Nesse contexto, o presente artigo tem como objetivo apresentar a experiência de introdução do BIM no curso de Arquitetura e Urbanismo de duas universidades federais, considerando sua repercussão e apropriação por parte dos alunos, dentro do processo de projeto. As universidades apresentadas incluem: Universidade Federal do Rio Grande do Norte (UFRN) e Universidade Federal do Ceará (UFC).

O estudo é parte de uma pesquisa de doutorado em andamento e compreende a etapa de caracterização do cenário onde se pretende intervir posteriormente. O método utilizado incluiu duas etapas: 1) etapa de caráter descritivo, onde foi levantado o contexto de implementação do BIM para cada universidade, considerando estrutura curricular e disciplinas envolvidas; 2 ) etapa de caráter exploratório, onde foi realizada a aplicação de questionário junto aos estudantes de disciplinas de projeto.

O contexto de implementação do BIM teve como objetivo identificar motivações e estratégias, a partir do cenário em que surgiram, análise do currículo e a inserção dentro $\mathrm{da}(\mathrm{s})$ disciplina(s). A aplicação de questionário buscou verificar como tais mudanças repercutiram junto aos estudantes, considerando seu domínio em relação aos diferentes meios de representação (ferramentas analógicas e digitais), como eles se apropriam espontaneamente de tais meios durante o processo de projeto, e as principais vantagens e dificuldades percebidas em relação ao uso do BIM. A amostra de estudantes foi definida a partir das disciplinas de projeto, considerando as turmas inseridas nas alterações descritas anteriormente, no que diz respeito à estrutura curricular e/ou disciplinas que abordem o BIM.

Considerando que a implementação do BIM no ensino ocorre de forma gradual, durante a descrição e análise das experiências serão considerados como referências os seguintes estágios (TOBIN, 2008):

- BIM 1.0 - com enfoque na modelagem paramétrica, a tecnologia é utilizada apenas 


\section{$2=$}

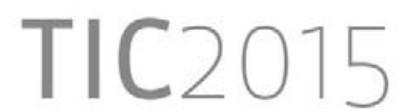

como uma ferramenta, pois o processo de trabalho ainda é individualizado, sem envolvimento e colaboração de outras disciplinas.

- BIM 2.0 - com enfoque na colaboração, a tecnologia é expandida para profissionais de outras disciplinas (multidisciplinar) e a interoperabilidade surge como termo essencial para que o BIM se torne um processo de trabalho.

- BIM 3.0 - com enfoque na prática integrada, amplia as possibilidades de interoperabilidade através de protocolos abertos e ambientes de trabalho virtuais, na busca de que todos os agentes envolvidos no empreendimento possam contribuir coletivamente, dentro das especificidades de suas disciplinas.

\section{CONTEXTO}

A seguir, será apresentado o contexto de introdução do BIM na grade curricular das universidades pesquisadas, buscando caracterizar e compreender o cenário onde a pesquisa foi realizada. Em ambos os casos, a motivação ocorreu a partir da chegada de novos professores, que introduziram o tema em disciplinas da área de representação, percepção e linguagem.

$\mathrm{Na}$ Universidade Federal do Rio Grande do Norte (UFRN), as discussões sobre o BIM tiveram início em 2010. Na grade curricular obrigatória, a disciplina selecionada para abordar o tema foi Desenho Auxiliado por Computador 02, ofertada para o $5^{\circ}$ semestre. Os objetivos da disciplina incluíam aprofundar os conhecimentos do aluno na área de Computação Gráfica, e complementar o conteúdo abordado na disciplina Desenho Auxiliado por Computador $01 \mathrm{com}$ técnicas avançadas para modelagem, aplicadas ao desenvolvimento e representação do projeto. Para tanto, a ferramenta BIM selecionada foi o software Revit Architecture (Autodesk), incluindo conteúdo de modelagem e documentação. É importante salientar que o $5^{\circ}$ semestre conta com a disciplina de Projeto Integrado 03 iniciativa recente na busca de associar os conteúdos de arquitetura, urbanismo e paisagismo em uma única disciplina de ateliê de projeto. No contexto do projeto integrado, os professores das disciplinas complementares, como estrutura, representação e conforto, também colaboram com as atividades de ateliê em participações programadas. Assim, é realizada uma interface direta com Desenho Auxiliado por Computador 02, permitindo o incentivo do uso do BIM nos trabalhos da própria disciplina de projeto.

Atualmente, o Projeto Político Pedagógico (PPP) do curso de graduação encontra-se em processo de revisão, permitindo a reestruturação de estratégias curriculares, mudanças em disciplinas existentes e proposição de novas disciplinas. Na área de Representação e Linguagem, mudanças estão sendo discutidas no intuito de inserir a abordagem dos novos meios digitais. Inicialmente, propõe-se que a disciplina Desenho Auxiliado por Computador 02 passe a se chamar "Modelagem de Informação da Construção (BIM)", consolidando o tema como conteúdo a ser abordado. Soma-se ainda, a proposta de uma disciplina optativa (Tópicos Avançados em BIM) para tratar de conceitos e práticas avançadas em BIM, como criação de templates e bibliotecas de famílias; desenvolvimento de legendas e quantitativos; e aplicações em interoperabilidade.

Na Universidade Federal do Ceará (UFC), a introdução do BIM teve início em 2009, e o tema passou a ser abordado na disciplina obrigatória Desenho Arquitetônico 02, ofertada para o $7^{\circ}$ semestre. $O$ objetivo foi a atualização do conteúdo e a revisão da metodologia para a construção de uma nova disciplina obrigatória (Desenho Arquitetônico Auxiliado por Computador - DAAC) que, a partir de mudanças no Projeto Político Pedagógico (2012), substituiu a anterior e passou a ser ofertada no $3^{\circ}$ semestre. A disciplina DAAC foi cursada pela primeira turma do novo currículo em 2013.2.

Inicialmente, buscou-se abordar o tema BIM considerando o uso de softwares diferentes, 
mas com as experiências realizadas ainda no antigo currículo, foi percebida a necessidade de dar enfoque a uma única ferramenta, em função do tempo da disciplina. Para tanto, foi selecionado o software Archicad (Graphisoft), e o conteúdo passou a incluir modelagem, documentação e a introdução de ambientes colaborativos (TeamWork). Para o semestre 2015.2, pretende-se realizar como trabalho final de DAAC a modelagem em BIM do projeto desenvolvido em Projeto Arquitetônico 01, disciplina de projeto do $3^{\circ}$ semestre. Busca-se, assim, ressaltar a importância do estudante aplicar os conceitos e ferramentas vistos ao longo da disciplina em uma atividade prática, com o objetivo de resolver uma situação problema.

Os contextos encontrados em ambas as universidades se assemelham por partirem de iniciativas individuais, introduzirem o tema em disciplinas de representação e se encontrarem na etapa BIM 1.0, devido ao enfoque em modelagem e documentação, e a restrição a estudantes de Arquitetura e Urbanismo.

Como diferenças, destacam-se a seleção dos softwares a serem trabalhados e o semestre em que as disciplinas sobre BIM são ofertadas. Para a UFRN, o conteúdo inclui o software Revit Architecture na disciplina de $5^{\circ}$ semestre, enquanto na UFC, atualmente é estudado o software Archicad na disciplina de $3^{\circ}$ semestre.

\section{APLICAÇÃO DOS QUESTIONÁRIOS}

A aplicação dos questionários buscou investigar a repercussão das mudanças realizadas em ambas as universidades, considerando uma coleta de feedback com os próprios estudantes. O modelo de questionário foi dividido em quatro blocos de temas específicos: 1. Caracterização do estudante; 2. Domínio das ferramentas; 3. Processo de projeto; 4. Building Information Modeling (BIM).

A caracterização do estudante incluiu universidade, semestre, experiência anterior com BIM e onde foi obtida essa experiência (disciplina, curso, workshop ou outro). A intenção foi situar o estudante dentro das mudanças ocorridas na grade curricular, identificando se ele já possuía conhecimento sobre BIM a partir de disciplina ou outras atividades.

Para o bloco sobre o domínio das ferramentas, foi pedido que o estudante marcasse o seu nível de domínio para uma lista de ferramentas apresentada, e apontasse quais delas ele utiliza espontaneamente ao projetar. Para evitar dúvidas sobre o nível de domínio, foram colocadas as seguintes descrições no próprio questionário: 1. Nenhum - não conhece; 2. Introdutório - abaixo da média; 3. Básico - mediano; 4. Avançado - acima da média. As ferramentas incluíram meios analógicos (croqui, maquete) e softwares de CAD tradicional ${ }^{2}$, BIM e modelagem paramétrica (AutoCAD, SketchUp, Archicad, Revit, Rhinoceros e Grasshopper). A partir desse bloco, buscou-se mapear qual grau de adoção e dificuldade os estudantes apontavam quanto às ferramentas BIM e estabelecer um comparativo com outros meios de representação.

Os blocos sobre processo de projeto e BIM incluíram perguntas diretas. Sobre o processo de projeto, solicitou-se: "Descreva como você dá início ao seu processo de concepção. Com que tipos de representação você estuda as ideias iniciais (ex. plantas, elevações, perspectivas, diagramas, conceitos) e utilizando quais ferramentas?" Quanto ao BIM, as perguntas foram: "Você utiliza ferramentas BIM para projetar? Em caso positivo, quais as VANTAGENS e quais as DIFICULDADES que você destacaria nessa utilização?" A intenção foi compreender como os estudantes trabalham o processo de projeto atualmente e sua percepção, tanto sobre os aspectos positivos do uso do BIM, quanto às suas dificuldades de

\footnotetext{
2 O termo CAD tradicional foi relacionado às gerações da ferramenta CAD que incluem o desenho auxiliado por computador (prancheta eletrônica) e modelagem geométrica (maquete eletrônica).
} 
adoção.

A amostra foi definida a partir das disciplinas de projeto arquitetônico, com início no semestre em que os alunos utilizam ferramentas BIM pela primeira vez. Na UFRN, os questionários foram aplicados a partir do $5^{\circ}$ semestre, onde os alunos têm a opção de utilizar o software Revit Architecture, conteúdo da disciplina Desenho Auxiliado por Computador 02, cursada em paralelo. Na UFC, a aplicação teve início na turma do $4^{\circ}$ semestre, onde os alunos têm a opção de utilizar o software Archicad, abordado na disciplina Desenho Arquitetônico Auxiliado por Computador (DAAC), cursada no $3^{\circ}$ semestre. Apesar de terem cursado uma disciplina de projeto arquitetônico no $3^{\circ}$ semestre, os alunos foram orientados a utilizar apenas instrumentos à mão por se tratar de sua primeira experiência projetual, não tendo empregado softwares ainda.

Assim, para cada universidade, o universo para a pesquisa contou com 5 turmas $\left(5^{\circ}\right.$ ao $9^{\circ}$ semestre) e 6 turmas ( $4^{\circ}$ ao $9^{\circ}$ semestre), respectivamente. Buscou-se uma amostra mínima de $50 \%$ para cada turma, alcançando 68 de 91 estudantes (75\%) na UFRN, e 108 de 151 estudantes (72\%) na UFC. A amostra detalhada de cada turma é apresentada no Quadro 1.

Quadro 1 - Amostra detalhada de estudantes, apresentando o número de respondentes por total de estudantes para cada semestre, nas universidades pesquisadas

\begin{tabular}{|c|c|c|}
\hline TURMA & UFRN & UFC \\
\hline $4^{\circ}$ SEM. & -- & $22 / 24$ \\
\hline $5^{\circ}$ SEM. & $12 / 20$ & $24 / 33$ \\
\hline $6^{\circ}$ SEM. & $15 / 22$ & $17 / 20$ \\
\hline $7^{\circ}$ SEM. & $16 / 18$ & $16 / 19$ \\
\hline $8^{\circ}$ SEM. & $15 / 15$ & $15 / 30$ \\
\hline $9^{\circ}$ SEM. & $10 / 16$ & $14 / 25$ \\
\hline TOTAL & $\mathbf{6 8 / 9 1}$ & $\mathbf{1 0 8 / 1 5 1}$ \\
\hline
\end{tabular}

Fonte: Autores, 2015.

\section{RESULTADOS}

A seguir, os resultados dos questionários serão apresentados para cada instituição separadamente, com posterior discussão e possíveis comparações. A apresentação será organizada na seguinte sequência: experiência anterior com BIM; grau de adoção dos meios de representação e como são aplicados no processo de projeto; vantagens e dificuldades percebidas para o uso do BIM.

As respostas quanto a experiência anterior e grau de adoção dos meios de representação serão apresentadas em percentual, considerando a análise quantitativa dos blocos de perguntas 1 e 2, que envolvem a caracterização dos estudantes e o domínio das ferramentas.

Sobre a aplicação no processo de projeto e vantagens/dificuldades percebidas para o uso do BIM, foram consideradas as respostas discursivas dos blocos de perguntas 3 e 4, sobre processo de concepção e BIM, respectivamente. Para tanto, foi utilizado o método de análise de conteúdo, permitindo o reconhecimento de respostas recorrentes e sua posterior organização em categorias. No caso das vantagens e dificuldades mencionadas pelos estudantes, as categorias foram quantificadas em percentual e só serão apresentadas aquelas que atingiram um mínimo de $10 \%$ dentre os comentários. O percentual considerou como amostra apenas os alunos que mencionaram alguma vantagem ou dificuldade em suas respostas discursivas, o que somou 42 respondentes de 68 consultados (62\%) para a UFRN, e 89 de $108(82 \%)$ para a UFC. Trechos de respostas também serão utilizados, ilustrando os comentários mais frequentes. 


\subsection{Universidade Federal do Rio Grande do Norte - UFRN}

Na UFRN, é importante ressaltar que todas as turmas consultadas pertencem à mesma grade curricular, vigente desde o ano letivo de 2008.1.

Em relação à caracterização dos estudantes, apenas 3\% afirmaram não possuir experiência anterior com BIM. Além da disciplina cursada durante o $5^{\circ}$ semestre pela maioria $(83 \%)$, também foram citados cursos (10\%), workshops (4\%) e outros $(6 \%)$, como experiência no exterior por intercâmbio ou tutoriais pela internet.

Para o grau de adoção dos diferentes meios de representação, as respostas foram consideradas tanto no total da amostra, como cada turma separadamente. $O$ intuito foi estabelecer comparativos entre os semestres, observando possíveis variações ao longo do período de implementação e interferências da adoção do BIM sobre as outras ferramentas.

As ferramentas mais adotadas espontaneamente pelos estudantes incluíram o croqui e o AutoCAD, ambos com $92 \%$ de respondentes, além do SketchUp com $82 \%$. Em seguida, ficaram o software BIM Revit (34\%) e a maquete (28\%). Os softwares Archicad, Rhinoceros e Grasshopper não foram mencionados na maioria das turmas, ficando abaixo de 3\%.

Analisando a adoção do BIM ao longo do período de implementação, é possível observar um aumento crescente quando as turmas são comparadas em relação ao uso do software Revit, abordado em disciplina obrigatória. Enquanto para o $9^{\circ}$ semestre a escolha do Revit foi de apenas $10 \%$ dos estudantes, o $5^{\circ}$ semestre apresentou mais da metade dos respondentes, com $58 \%$.

Em relação aos outros meios de representação, é possível observar que apenas o SketchUp apresenta uma redução considerável em relação ao aumento de adoção do Revit. Por outro lado, independente do uso do BIM, o croqui e o AutoCAD mantêm a predominância em todas as turmas, enquanto a maquete foi a menos mencionada.

As variações podem ser observadas a partir da Figura 1, onde é apresentado o gráfico com o percentual de adoção para os meios de representação mais significativos, diferenciado por semestre. É possível perceber a tendência crescente para o uso do Revit, que coincide com a redução do SketchUp. Croqui, maquete e AutoCAD mantem variações independentes, não sendo possível estabelecer uma tendência.

Figura 1 - Percentual de adoção para cada meio de representação, diferenciado por semestre para a UFRN

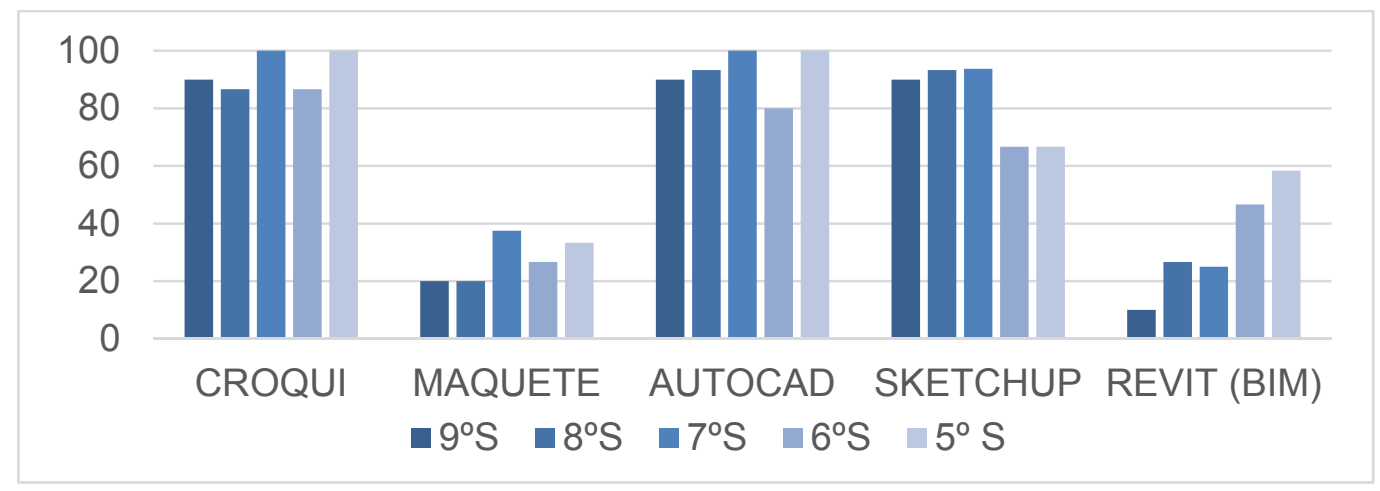

Fonte: Autores, 2015.

Analisando as respostas discursivas quanto ao início do processo de concepção, a maioria dos estudantes mencionou o croqui para o estudo de ideias iniciais $(71 \%)$, enquanto o uso conjunto do AutoCAD e SketchUp foi destacado para o desenvolvimento do projeto já em andamento (37\%). $31 \%$ dos estudantes associaram o SketchUp ao estudo de volumetria e 
desenvolvimento de perspectivas, enquanto $26 \%$ associaram o AutoCAD à precisão de dimensionamento e ao desenho da planta baixa. Dentre os softwares BIM, o Revit foi mencionado por $10 \%$ dos estudantes, como meio para desenvolvimento posterior do projeto.

A principais vantagens do uso do BIM mencionadas pelos estudantes incluíram a geração automática de cortes e elevações (43\%), somado ao modelo tridimensional (36\%), o que permite uma maior agilidade e praticidade dentro do processo de projeto (36\%). O aumento da integração e controle das alterações $(12 \%)$, além da qualidade da apresentação final $(12 \%)$ também foram citados. O Quadro 2 apresenta trechos de respostas acerca das vantagens do uso do BIM para ilustrar os comentários mais recorrentes.

Quadro 2 - Trechos de respostas acerca das vantagens do uso do BIM

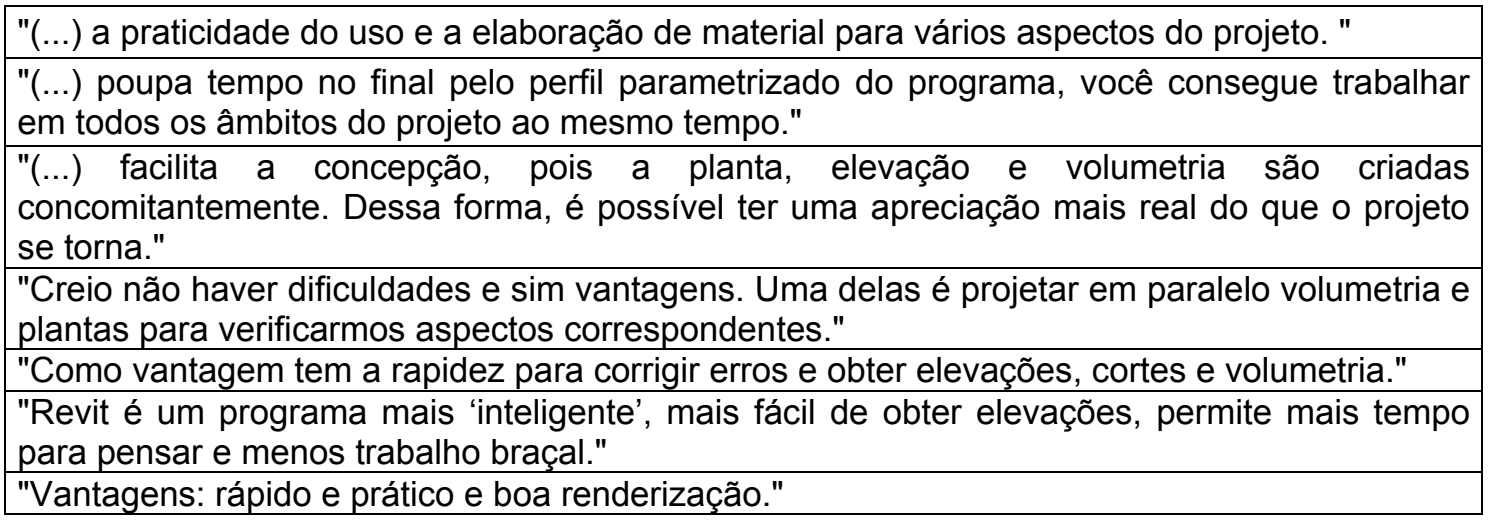

Fonte: Autores, 2015.

As principais dificuldades mencionadas dizem respeito à falta de domínio do software e a dificuldade de adaptação em relação aos meios já utilizados (38\%). Também foram citados a falta de liberdade projetual (19\%), o alto nível de complexidade das ferramentas $(14 \%)$ e a carência de bibliotecas de famílias e objetos (14\%). O Quadro 3 apresenta trechos de respostas dos estudantes acerca das dificuldades do uso do BIM para ilustrar os comentários mais recorrentes.

Quadro 3 - Trechos de respostas acerca das dificuldades do uso do BIM

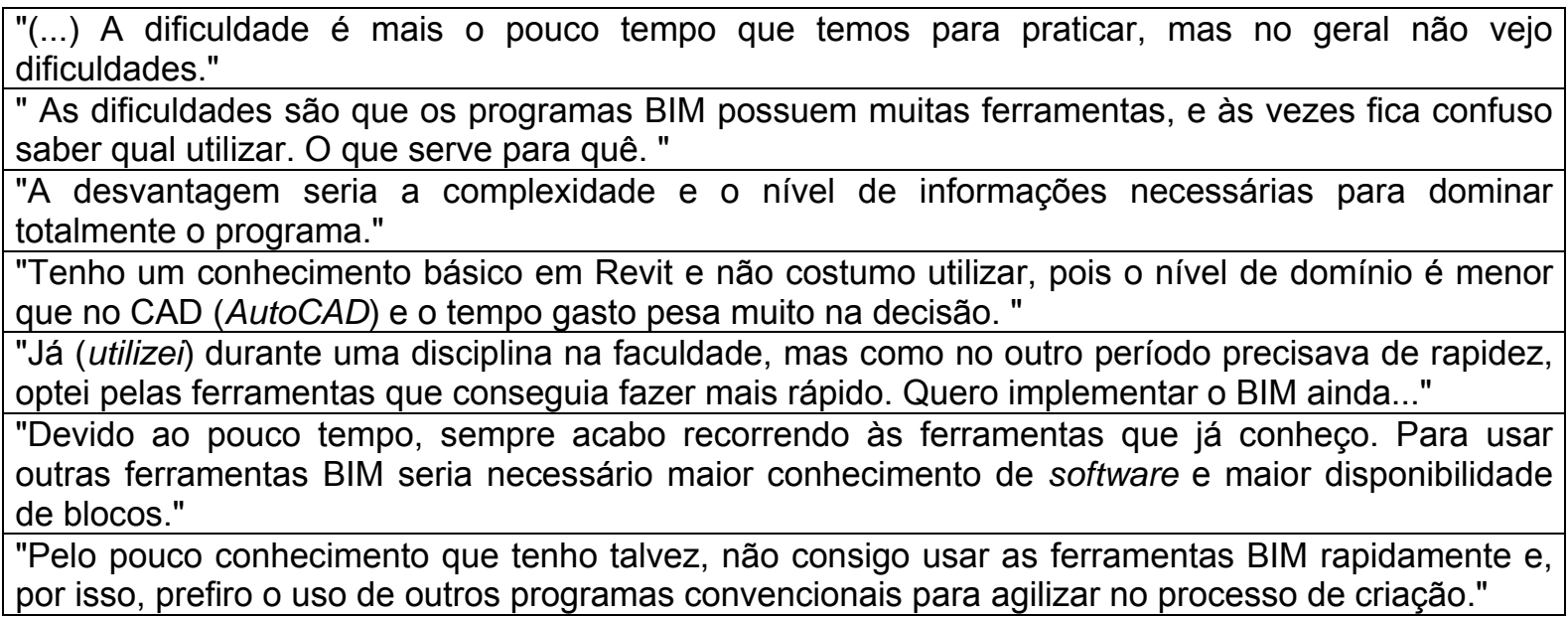

Fonte: Autores, 2015.

\subsection{Universidade Federal do Ceará - UFC}

$\mathrm{Na}$ UFC, é importante ressaltar que as turmas do $4^{\circ}$ ao $6^{\circ}$ semestre são pertencentes ao 
atual currículo, vigente desde 2012.2, enquanto as do $7^{\circ}$ ao $9^{\circ}$ pertencem ao currículo antigo. Para a análise de determinados aspectos essa diferenciação será estabelecida com efeitos comparativos.

Em relação à caracterização dos estudantes, considerando o total da amostra com 108 respondentes, 14\% afirmaram não possuir experiência anterior com BIM. Além da disciplina obrigatória cursada pela maioria $(71 \%)$, também foram citados cursos $(27 \%)$; workshops $(13 \%)$ e outros $(6 \%)$, como estágio e monitoria.

Para o grau de adoção dos diferentes meios de representação, as respostas foram analisadas a partir dos diferentes currículos (atual e antigo) e em cada turma separadamente. O intuito foi estabelecer comparativos entre os dois modelos de currículo, observando possíveis variações no período de implementação e interferências da adoção do BIM em relação às outras ferramentas.

Segundo as turmas do currículo antigo (45 estudantes), as ferramentas mais adotadas espontaneamente são o AutoCAD (87\%), croqui (84\%) e SketchUp (69\%), respectivamente. Em seguida, foram mencionados os softwares BIM Archicad (42\%) e Revit (16\%), assim como a maquete (16\%). Com baixa utilização, Rhinoceros e Grasshopper atingiram menos de $10 \%$.

Nas turmas do currículo atual (63 estudantes), as ferramentas mais mencionadas foram o software BIM Archicad (92\%) e o croqui (86\%). AutoCAD e SketchUp apresentaram redução de uso $(51 \%$ e $26 \%$, respectivamente), enquanto a maquete se manteve estável $(18 \%)$. Revit, Rhinoceros e Grasshopper pontuaram abaixo de $10 \%$.

As variações podem ser observadas a partir da Figura 2, onde é apresentado o gráfico com o percentual de adoção para os meios de representação mais significativos, diferenciado por semestre. É possível perceber uma tendência crescente e estabilização para o uso do Archicad, o que coincide com a redução clara do AutoCAD e SketchUp. Croqui e maquete mantiveram variações independentes, não sendo possível estabelecer uma tendência.

Figura 2 - Percentual de adoção para cada meio de representação, diferenciado por semestre para a UFC

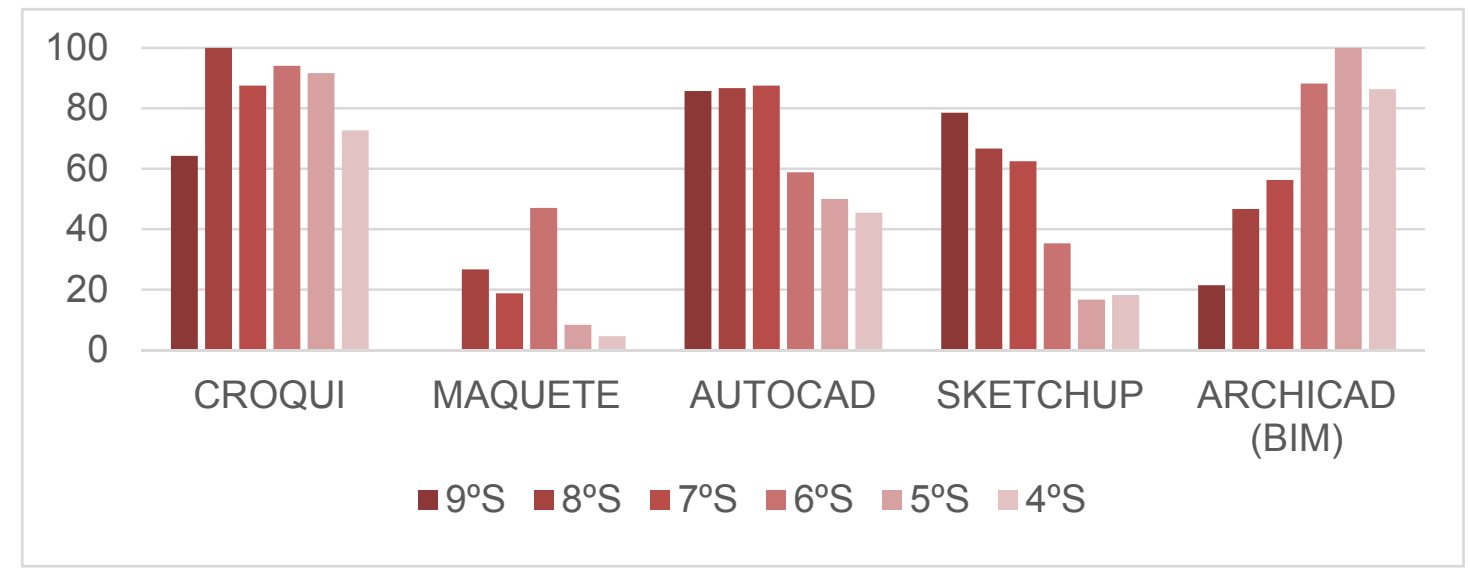

Fonte: Autores, 2015.

Analisando as respostas discursivas quanto ao início do processo de concepção, a maioria dos estudantes descreveu o uso do croqui para o estudo de ideias iniciais, seguido de softwares para o desenvolvimento do projeto. O uso de software foi relacionado à investigação da volumetria e maior precisão no dimensionamento.

Após os estudos iniciais em croqui, cerca de $40 \%$ dos estudantes do antigo currículo mencionaram utilizar AutoCAD e/ou SketchUp, 12\% apenas o Archicad, e $8 \%$ afirmaram 
mesclar os três softwares. Quanto ao currículo atual, $41 \%$ dos estudantes mencionaram o uso do croqui associado ao Archicad, e $14 \%$ ao computador, sem especificar o software. Aqueles que mencionaram Revit, AutoCAD e/ou SketchUp não atingiram percentual representativo, abaixo de $10 \%$.

A principais vantagens do uso do BIM apontadas pelos estudantes do antigo currículo coincidiram com aquelas encontradas na UFRN: geração do modelo tridimensional $(40 \%)$ e dos cortes/elevações (27\%), permitindo uma maior agilidade e praticidade no processo de projeto $(27 \%)$. Foram mencionadas, ainda, vantagens relacionadas ao caráter paramétrico do modelo (23\%); e a interface intuitiva do programa (13\%).

O currículo atual também apresentou vantagens semelhantes, apenas com um percentual maior dentro da amostra de respondentes: geração do modelo tridimensional (58\%), maior praticidade e rapidez (34\%) e cortes/elevações (32\%). Foram mencionados, ainda, os benefícios para a visualização formal e noção espacial (29\%); o caráter paramétrico do modelo que fornece significado aos objetos como componentes construtivos (24\%); e a maior integração/controle do projeto (15\%).

O Quadro 4 apresenta trechos de respostas acerca das vantagens do uso do BIM para ilustrar os comentários mais recorrentes, diferenciados por currículo atual e antigo.

Quadro 4 - Trechos de respostas acerca das vantagens do uso do BIM

\begin{tabular}{|l|}
\hline Currículo Atual \\
\hline "As vantagens são uma economia de tempo, dinâmica entre todos os elementos de projeto \\
(plantas, elevações, cortes, perspectivas)." \\
\hline "O Archicad facilita bastante meu projeto, pois as alterações feitas em planta se rebatem nos \\
cortes e perspectivas, tornando o processo mais coeso." \\
"Vantagens: o entendimento das partes da modelagem como um objeto com significados e \\
processos definidos." \\
\hline "A principal vantagem é o grande volume de informações que o programa fornece de maneira \\
tal que podemos manipular plantas, cortes, fachadas e perspectivas simultaneamente." \\
\hline "As vantagens do BIM são a agilidade para fazer os cortes, maior coerência do projeto (todas \\
as plantas representam o modelo, sem diferença entre elas), melhor visualização do \\
processo construtivo, dentre outras..." \\
\hline Currículo Antigo \\
\hline "Uma das principais vantagens é a possibilidade de imediatamente após um desenho \\
bidimensional detectar a consequência tridimensional, combatendo o desenho alienado." \\
\hline "Vantagens: facilidade para gerar os desenhos 2D e 3D, mudança de atributos, diferentes \\
formatos de apresentação e uma visão total e mais rápida do projeto." \\
\hline "A rapidez de ajustes quando se encontra problemas durante o processo de projeto considero \\
a vantagem maior das ferramentas BIM." \\
\hline "Tenho um domínio maior do resultado final do edifício quando trabalho no BIM, é uma forma \\
muito mais lógica de trabalhar." \\
\hline
\end{tabular}

Fonte: Autores, 2015.

As dificuldades mais mencionadas pelos estudantes do antigo currículo também coincidiram com algumas encontradas na UFRN: falta de domínio do software $(20 \%)$, falta de liberdade projetual $(20 \%)$, e o alto nível de complexidade das ferramentas $(20 \%)$. Foi mencionada, ainda, a dificuldade na etapa de documentação, compreendida como a apresentação final das pranchas com desenhos técnicos (10\%).

Para o currículo atual, as dificuldades mencionadas pela maioria dos estudantes foram o alto nível de complexidade das ferramentas e as informações interconectadas (34\%), seguidas apenas de falta de domínio do programa (19\%) e etapa de documentação $(10 \%)$. Por fim, o Quadro 5 apresenta trechos de respostas acerca das dificuldades do uso do BIM 
para ilustrar os comentários mais recorrentes, diferenciados por currículo atual e antigo.

Quadro 5 - Trechos de respostas acerca das dificuldades do uso do BIM

\begin{tabular}{|l|}
\hline Currículo Atual \\
"As 'desvantagens' são a dificuldade de apreender o programa, são muitos comandos, muitas \\
variáveis que me deixam insegura, mas que com o tempo e o uso se tornaram intuitivas." \\
\hline " A desvantagem está na restrição de processo criativo relativo ao nível de conhecimento \\
sobre o programa." \\
\hline "A desvantagem seria o fato de que as ferramentas são muito interconectadas, de forma que \\
determinadas mudanças exigem a manipulação de várias ferramentas." \\
\hline " O que acho mais desvantajoso é o fato de as informações estarem tão "amarradas" que um \\
erro acumulativo é difícil de resolver se passar despercebido." \\
\hline " A dificuldade se dá na complexidade de informações que deve conter o projeto." \\
\hline Currículo Antigo \\
\hline "Como dificuldade que eu tive foi porque estava projetando e começando a aprender ao \\
mesmo tempo, então alguns comandos eram mais complicados." \\
\hline " Ainda preciso dominar totalmente a ferramenta, para maior liberdade projetual. " \\
\hline "(...)as dificuldades que encontro geralmente estão ligadas ao meu grau de domínio da \\
ferramenta e à falta de conhecimento para representar da maneira que imagino." \\
\hline "Normalmente o BIM é subutilizado por mim, no sentido de me servir apenas para modelar \\
em 3D e não em todas as suas possibilidades."
\end{tabular}

Fonte: Autores, 2015.

\subsection{Discussão dos resultados}

Alguns aspectos em comum foram percebidos entre os resultados de ambas as universidades, como o aumento crescente de adoção dos softwares BIM; e a predominância de processos híbridos de representação, através da associação do croqui (ideias iniciais) e programas computacionais (desenvolvimento do projeto).

No caso da UFRN, a adoção do Revit aumentou de $10 \%$ para $58 \%$ entre as turmas de $9^{\circ}$ e $5^{\circ}$ semestres; enquanto na UFC, houve um aumento de $42 \%$ para $92 \%$ no uso do Archicad, quando comparados os currículos antigo e atual. Destaca-se que esse aumento pode ser relacionado a uma substituição gradativa do AutoCAD e/ou SketchUp, enquanto o croqui e a maquete mantiveram variações independentes, não sendo reconhecida nenhuma tendência.

Quanto à percepção dos estudantes em relação às vantagens para o uso do BIM, no geral foi destacada a integração entre o modelo tridimensional e suas vistas bidimensionais (plantas, cortes e elevações). A princípio as melhorias percebidas dizem respeito às suas características como ferramenta, relacionadas aos aspectos paramétricos dos modelos BIM: agilidade, praticidade, visualização da forma/espaço e controle de alterações. Em um momento posterior, essa percepção é aprimorada para a compreensão do modelo BIM como a associação de objetos com "significado", aproximando representação e realidade construtiva. As consequências para cada tomada de decisão se tornam mais claras e trazem um maior comprometimento com o produto final.

Por outro lado, essas características geram um aumento de complexidade, tanto em relação às possibilidades da ferramenta quanto à inserção de informações, que deverão ser trabalhadas em conjunto. Assim, a adaptação em relação aos softwares anteriormente utilizados e o tempo de prática em ferramentas e processos mais complexos foram as dificuldades mais destacadas. Também é importante colocar que o nível de domínio dos meios de representação utilizados está diretamente relacionado à liberdade criativa do projetista, aspecto ressaltado pelos próprios estudantes. 
Apesar das experiências apresentadas se caracterizarem como etapa BIM 1.0, por seu caráter introdutório e restrito à ferramenta, já apresentam desafios e contribuições para a implementação gradativa do tema no ensino em Arquitetura e Urbanismo.

Quando comparados os diferentes perfis, percebe-se que aqueles estudantes que passaram a estudar o BIM a partir do $5^{\circ}$ ou $7^{\circ}$ semestre (UFRN e antigo currículo da UFC) tiveram menor grau de adoção e maior dificuldade de adaptação por já estarem acostumados a outras ferramentas digitais e metodologias projetuais. Alguns respondentes chegaram a afirmar que preferem utilizar as ferramentas que já conhecem em função do tempo ou que subutilizam as ferramentas BIM apenas para a modelagem tridimensional.

Por outro lado, os comentários das turmas que estudaram o BIM no $3^{\circ}$ semestre e começaram a utilizá-lo em disciplina de projeto a partir do $4^{\circ}$ destacaram a complexidade referente ao software e às informações que alimentam o modelo de modo interconectado. As características da modelagem paramétrica passaram a ser percebidas tanto em suas vantagens quanto consequências.

É importante destacar que cada instituição deve realizar um planejamento prévio para a adoção do BIM, considerando seu contexto específico no que diz respeito às dificuldades práticas, nível de formação que o curso deseja fomentar, organização curricular, método de ensino-aprendizagem, dentre outros (CHECCUCCI, 2014). Porém, considerando o resultado da presente pesquisa, alguns aspectos podem ser ressaltados.

O BIM destaca-se por sua complexidade, no que diz respeito às diferentes possibilidades das ferramentas e ao gerenciamento integrado de informações. Considerando que a adoção completa do paradigma BIM (etapas BIM 1.0, BIM 2.0 e BIM 3.0) não ocorre de imediato, é importante que as grades curriculares vislumbrem a oportunidade do estudante se apropriar do tema de modo gradativo ao longo do curso, com aumento crescente de complexidade. Pode-se utilizar como base o processo de aprendizagem através da reflexão-na-ação (SCHÖN, 2000): o aluno parte do reconhecimento e aplicação de operações padrão, para raciocinar sobre problemáticas características do processo, até ser capaz de enfrentar novas formas de compreensão e ação. Assim, além de disciplinas que envolvam o estudo de conceitos e ferramentas, é necessária a aplicação do tema em atividades práticas e resolução de situações problema. Porém, considerando que o BIM 3.0 envolve práticas integradas, interoperabilidade e os diferentes agentes envolvidos em um empreendimento, sua adoção no ensino deve considerar a prática de projeto em equipe e o envolvimento de outros cursos em áreas afins.

Também foi reconhecida uma tendência de adoção de processos híbridos de representação, caracterizado pelo uso integrado de meios analógicos e digitais. Nesse caso, a introdução do BIM no ensino deve prever suas possíveis interfaces com outras ferramentas, considerando potencialidades/limitações e uma contribuição mútua entre os diferentes meios. Dessa forma, seria possível evitar rupturas no ensino dos diferentes processos de representação, que acabam exigindo posteriores adaptações por parte dos estudantes.

\section{CONSIDERAÇÕES FINAIS}

A presente pesquisa buscou apresentar a experiência de introdução do BIM em dois cursos de Arquitetura e Urbanismo, assim como sua repercussão e apropriação por parte dos estudantes. Considerando o contexto de implementação e a análise dos questionários aplicados em disciplinas de projeto, foi possível levantar aspectos quanto ao grau de adoção do BIM, sua introdução no processo de projeto, vantagens e dificuldades.

Foi percebido um maior grau de adoção do BIM por parte dos estudantes que tiveram contato com o tema ainda na primeira metade do curso, e a tendência de substituição dos programas de CAD tradicional como AutoCAD e SketchUp. Por outro lado, a partir da 
variação dos gráficos de percentual de adoção, croqui e maquete não apresentaram interferência aparente, observando-se a tendência a processos híbridos de representação, com o uso conjunto de meios analógicos e digitais.

As experiências em ambas as universidades foram situadas no BIM 1.0, onde são destacados seus aspectos como ferramenta, principalmente a modelagem paramétrica. As vantagens percebidas pelos estudantes ressaltam a integração entre o modelo tridimensional e suas vistas bidimensionais, conferindo ao processo de projeto agilidade, praticidade, melhor visualização, integração, controle e aproximação entre representação e construção. Por outro lado, foram ressaltados o aumento de complexidade, a necessidade de um processo de adaptação, e tempo de prática para o domínio de ferramentas e processos.

Como consequência para o ensino, é importante que a grade curricular das universidades vislumbre a oportunidade do estudante se apropriar do BIM de modo gradativo ao longo do curso, com aumento crescente de complexidade. Nesse processo, destaca-se a compreensão das possíveis interfaces entre o BIM e outras ferramentas, suas potencialidades/limitações $\mathrm{e}$ as contribuições mútuas entre os diferentes meios de representação. Ressalta-se, ainda, que após a introdução do BIM como ferramenta, os cursos de Arquitetura e Urbanismo deverão considerar discussões que vislumbrem aspectos dos estágios BIM 2.0 e BIM 3.0, o que inclui colaboração, interoperabilidade e práticas integradas. Para tanto, faz-se necessária a inserção do tema em disciplinas para além da área de representação e a troca de experiências com outros cursos de áreas afins.

\section{AGRADECIMENTOS}

Agradecimentos à CAPES (Coordenação de Aperfeiçoamento de Pessoal de Nível Superior) e a todos que participaram da pesquisa através dos questionários, incluindo tanto os estudantes que colaboraram com suas respostas, quanto os professores de projeto que disponibilizaram espaço em suas aulas para que fosse realizada a aplicação.

\section{REFERÊNCIAS}

CHECCUCCI, E. S. Ensino-aprendizagem de BIM nos cursos de graduação em Arquitetura e Engenharia Civil. In: ENCONTRO DA ASSOCIAÇÃO NACIONAL DE PESQUISA E PÓS GRADUAÇÃO EM ARQUITETURA E URBANISMO, 3., 2014, São Paulo. Anais... São Paulo Campinas: UPM-PUCCAMP, 2014.

KRYGIEL, E.; NIES, B. Green BIM: successful sustainable design with building information modeling. Wiley Publishing, Inc. Indianapolis, Indiana, 2008. ISBN: 978-0-470-23960-5.

RUSCHEL, R. C. To BIM or not to BIM? In: ENCONTRO DA ASSOCIAÇÃO NACIONAL DE PESQUISA E PÓS-GRADUAÇÃO EM ARQUITETURA E URBANISMO, 3., 2014, São Paulo. Anais... São Paulo - Campinas: UPM-PUCCAMP, 2014.

SCHÖN, D. A. Educando o Profissional Reflexivo: um novo design para o ensino e a aprendizagem. Porto Alegre: Artmed Editora, 2000.

SUCCAR, B. Building information modelling framework: A research and delivery foundation for industry stakeholders. Automation in Construction, 18(3), pp. 357-375. 2009.

TOBIN, J. Proto-Building: To BIM is to Build. AECbytes, 28 mai. 2008. Disponível em: <http://www.aecbytes.com/buildingthefuture/2008/ProtoBuilding.html > Acessado em: março. 2011 